\title{
Research on the Status Quo and Countermeasures of College Students' Entrepreneurship Incubator Platform Construction \\ -- Take Yulin College as an Example
}

\author{
Jiang Liu ${ }^{1, a^{*}}$, Xinzhuo Jiang ${ }^{2, b}$ and Xiaohon $\mathrm{Hu}^{3, \mathrm{c}}$ \\ ${ }^{1}$ School of Management, Yulin University, China, 719000 \\ ${ }^{2}$ School of Foreign Languages, Yulin University, China, 719000 \\ ${ }^{3}$ School of Management, Yulin University, China, 719000 \\ a52186531@qq.com, b250883726@qq.com, ${ }^{\mathrm{c}} 526706728 @ q q . c o m$ \\ * please mark the corresponding author with an asterisk
}

\begin{abstract}
Keywords: Entrepreneurship; Entrepreneurship incubation platform; Operation mechanism; Coordination
\end{abstract}

\begin{abstract}
In recent years, the construction of college students' entrepreneurship incubation platform has been in full swing, and has become an important front for colleges and universities to implement entrepreneurship education. However, it still faces some difficulties in practice. In this paper, the colleges and universities in Yulin City are taken an example to sort out and discuss the development of college graduates' entrepreneurial incubating platform from the three dimensions: status quo, dilemma and countermeasures, with a view to inspiring the construction and innovation of college students' entrepreneurship incubation platform.
\end{abstract}

\section{Introduction}

In 2015, "mass entrepreneurship and innovation" was promoted as a national strategy. Under the government-driven promotion, the incubation platform for entrepreneurship emerged like a mushroom. The government, enterprises, and universities were all the main players, and the number of incubating enterprises increased rapidly.

In 2015, the Human Resources and Social Security Bureau of Yulin City and the Finance Bureau jointly issued the "Measures for the Management of the Identification of the Start-up Incubation Base in Yulin City (Interim)". Subsequently, the Municipal Bureau of Science and Technology issued the Interim Measures for the Management of Public Space in Yulin City. The two "measures" have defined the types, objects, standards, methods of formation, qualifications, assessment, appraisal, and policy support of the city's "entrepreneurship incubator base" and "public space".

In May 2015, the Yulin College Graduate Entrepreneurship Incubation Base was established and put into use in July. There are 24 projects, including hi-tech, electronic information, cultural industries, modern product $\mathrm{R} \& \mathrm{D}$, sales, and business operations. In order to manage and use this base, the school has established the "Zhulin College Undergraduate Entrepreneurship and Incubation Base Construction Leading Group" responsible for the guidance and coordination of the base. In December 2016, this was awarded the "Shaanxi Zhongchuang Space Incubation Base" by the Science and Technology Department of Shaanxi Province.

\section{Status Quo}

Basic Situation of Entrepreneurship Incubation Base of Yulin College. The Entrepreneurship Incubation Base is a college student entrepreneurial practice base managed and operated by Yulin College. It has the incubator function. Through the provision of entrepreneurial practice venues and related support policies, college students are provided with entrepreneurship practice platforms, students are encouraged to cultivate and enhance their innovative and entrepreneurial skills in the 
course of setting up business entities and entrepreneurship practices. The entrepreneurship incubator base provides free office space for entrepreneurs and entrepreneurial teams, and it covers an area of 2,800 square meters. Among them, there are 68 independent office areas and 4 public activity areas (business negotiation rooms) equipped with computer desks and chairs, filing cabinets, network cables, power supplies, computers, printers and other office facilities.

\section{Services and Major Preferential Policies that Can be Enjoyed for Entering the Incubation Project.}

Provide free office space of about 20 square meters;

Give priority to start-up loans in Shaanxi Province and Yulin City; prioritize implementation of tax and fee reduction and subsidy policies;

Have the priority to enjoy the subsidy program for undergraduate program (1,000 yuan per person per month, implemented from January to June each year, totaling 6,000 yuan);

Provide follow-up services such as entrepreneurship project counseling, entrepreneurial salons, business startup projects, and entrepreneurship enhancement.

\section{Entrepreneurship Incubation Base's Entry Conditions.}

The individual or team leader of the entrepreneur must be a full-time college student who is a full-time student of our school or who has graduated within five years (a graduate of 2011 and later);

Individuals or teams of entrepreneurs voluntarily accept the relevant management system of the entrepreneurship incubation base and abide by the implementation;

Venture projects should have a certain degree of innovation or good market potential;

Individuals or teams of entrepreneurs need to determine operating items according to market 5 . Individuals or teams of entrepreneurs should have certain project start-up capital and the ability to take risks;

After an individual or team of entrepreneurs enters a business incubator base, they must ensure that they can work normally at the base;

Entrepreneurship individuals or team leaders who start entrepreneurial activities need to be approved by parents and their department.

\section{Dilemma}

Lack of Clear Value Recognition and Clear Functional Positioning. Through the comparison of the model entrepreneurial platform and the ordinary entrepreneurial platform in the province, it can be found that some colleges and universities are unclear and uncertain about the function orientation of the entrepreneurship platform. They have recognized the public welfare, innovation, and serviceability of the entrepreneurial platform, but they lack understanding of the virtuality, synergy, and marketization and enterprise-based entrepreneurial platform. They have implemented the functions of classification and hierarchy without active integration of social development, school reality, student needs and teaching students in accordance with their aptitude, adapting to the school situation and the local conditions, thus forming one mechanism and standard that is void and suits all.

Lack of Coordination Within the School and the co-Construction Mechanism of the Government, School, and Enterprise. Due to the lack of value recognition of entrepreneurship education in ordinary colleges and universities, especially the congenital deficiency of entrepreneurial culture in university campuses, it is difficult to promote entrepreneurship education and entrepreneurship practice. In the entire school education system, there is a clear disadvantage. If there is not enough top-level design and there is no strong support from the decision-makers, it will be difficult. Compared with social resources, the platform advantage of the college's entrepreneurship incubator platform has not been formed. The social network resources support from universities, government, and social forces to the university's entrepreneurial incubation is still not in place. 


\section{Countermeasures}

Clarify Functional Positioning And Enhance Top-level Design. As for the above issues, the author believes that the first thing to be solved is the need to further clarify the functional orientation of college students' entrepreneurship incubation platform. Based on this, the first step is to clarify the main body of construction. Although the investment incubators for undergraduates in colleges and universities are divided into different types, such as "direct management of colleges and universities", "school-enterprise cooperation" and "school co-construction", the overall construction is dominated by schools. The main investment entities are universities, which belong to the public incubation organization model, so it should serve the training objectives of colleges and universities. The second step is to clarify the service subject. Obviously, the service subject is college students. It is a college student entrepreneur who has the will to enter the business venture to enter the school's entrepreneurship platform for practical training, or discovers that entrepreneurial opportunities have entered the school's entrepreneurship platform for incubation. The third step is to clarify the service functions. The main function of the entrepreneurship incubation platform is to provide entrepreneurs with shared operating services, help start-ups reduce costs, and enhance their chances of success. It also has the dual characteristics of public services and market services. It also reflects public welfare and serviceability. innovative and market-oriented, collaborative features. On this basis, the school must carry out top-level design at the strategic level and incorporate personnel, capital, and facility construction into overall planning and system advancement.

Build a Collaborative Mechanism to Provide Continuous Protection. First, deepen internal collaboration in universities. The entrepreneurship platform is an important part of the entrepreneurship education system in colleges and universities. Colleges and universities should be arranged at the institutional level to form organizational coordination within the school: set up a special leadership group, form a regular joint conference system, clarify the responsibilities of the various functional departments, and promote coordination.

Second, to build external collaboration among government colleges and universities. First, platform collaboration. The government and multi-subjects of enterprises participate in the construction of colleges and universities; the establishment of an integrated information service platform for the entrepreneurial park will enable the interconnection and interoperability of information within and outside the school through network links and promote the sharing of resources. Second, service collaboration. The government should make policies into the school, serve the park, and promote various types of intermediary organizations into the campus by providing services to the public, providing professional public services, and building "one-stop" service platforms with colleges and universities. Entrepreneurs should consciously join the expert service group and actively provide entrepreneurs with "one-stop services" such as screening, risk assessment, and operation support. Finally, financing collaboration. Give full play to the main role of the government, universities and enterprises, and build a diversified college students' venture capital support system with a wide range of channels and various forms. Establish government-led college students' venture capital fund with the participation of colleges, universities, enterprises and all walks from the society.

\section{Acknowledgements}

Planning Project:

Special fund planning project of social science federation in Yulin city in 2017. (Project Number: YLSKGH2017-16)

Yulin university-industry cooperation project in 2016 (Project Number: 2016CXY-10) 


\section{References}

[1] J.Q. Zhang: Forum on Science and Technology in China, (2017) No.1, p.305 (In Chinese)

[2] Zh.H. Yang: Modern Management Science, (2016) No.7, p.45 (In Chinese)

[3] Sh.Z. Gu: Hubei Social Sciences, (2016) No.7, p. 87 (In Chinese)

[4] H, Yu and W.W. Ye: Research in Higher Education of Engineering, (2016) No.3, p.100 (In Chinese)

[5] Ch.H. Tao: China Development Observation, (2016) No.4, p.56(In Chinese)

[6] Sh.M.Hui: Review of Economic Research, (2016) No.7, p.36 (In Chinese)

[7] Sh.C. Zhang: Reform of Economic System, (2016) No.1, p.14(In Chinese)

[8] Y.Q. Liu, F.Y. Lv and J. Mao: Journal of Chinese Academy of Governance, (2016) No.6, p.35 (In Chinese)

[9] Ch.M. Wang and T. Wu: Journal of Zhejiang University(Humanities and Social Sciences), (2016) No.1, p.131 (In Chinese)

[10]W. Lv: Frontiers , (2015) No.22, p.6 (In Chinese)

[11] B.H. Jing: Science \& Technology Progress and Policy , (2015) No.03, p.11 (In Chinese)

[12]X.W. Li: Academic Forum , (2015) No.01, p.176 (In Chinese)

[13]Y.X. Cheng : Research in Educational Development, (2010) No.21, p.84 (In Chinese) 